Research Paper

\title{
Expression analysis for genes involved in arachidonic acid biosynthesis in Mortierella alpina CBS 754.68
}

\author{
Hamid-Reza Samadlouie ${ }^{1}$, Zohreh Hamidi-Esfahani ${ }^{1}$, Seyed-Mehdi Alavi ${ }^{2}$, \\ Boshra Varastegani ${ }^{3}$ \\ ${ }^{1}$ Department of Food Science and Technology, Faculty of Agriculture, \\ Tarbiat Modares University, Tehran, Iran. \\ ${ }^{2}$ National institute for Genetic Engineering and Biotechnology, Tehran, Iran. \\ ${ }^{3}$ Food Technology Division, School of Industrial Technology, Universiti Sains Malaysia, Pulau, \\ Pinang, Malaysia.
}

Submitted: February 26, 2013; Approved: September 9, 2013

\begin{abstract}
The time courses for production of fungal biomass, lipid, phenolic and arachidonic acid (ARA) as well as expression of the genes involved in biosynthesis of ARA and lipid were examined in Mortierella alpina CBS 754.68. A significant increase in the arachidonic acid content in lipids that coincided with reduced levels of lipid was obtained. Reduced gene expression occurred presumably due to the steady reduction of carbon and nitrogen resources. However, these energy resources were inefficiently compensated by the breakdown of the accumulated lipids that in turn, induced upregulated expression of the candidate genes. The results further indicated that the expression of the GLELO encoding gene is a rate-limiting step in the biosynthesis of ARA in the early growth phase.
\end{abstract}

Key words: Mortierella alpina, arachidonic acid, lipid, gene expression, real time PCR.

\section{Introduction}

Arachidonic acid (5, 8, 11, 14-eicosatetraenoic acid, ARA), a long chain polyunsaturated fatty acid (PUFA) of the $n-6$ class, plays important roles in the structure and function of biological membranes (Jang et al., 2005). Lower fungi of Zygomycetes especially Mortierella alpina were served as rich sources of PUFAs (Sing and Ward, 1997).

Attempts to describe the biosynthetic pathways of PUFA have been continued for a long time, but it is lately that the genes regulating key steps in the biosynthesis have been identified (Shimizu et al., 2003). Genes that are involved in ARA and lipid biosynthesis are classified into three groups: desaturase, elongase and malic encoding genes. Malic enzyme is the providing NADPH for fatty acid biosynthesis in Mortierella alpina (Zhangy and Ratledge, 2008). ARA is produced through the n-6 pathway, which involves $\Delta 9, \Delta 12, \Delta 6$ and $\Delta 5$ desaturases and elongases (GLELO and MALCE1). The elongases, GLELO and MALCE1, have been reported to catalyse the elongation of gamma linolenic acid (18:3n-6) to dihomo- $\gamma$-linolenic acid (20:3n-6) and C16 to C18, respectively (Sakuradani et al., 2009).

In the previous report, the authors proposed a growth model capable of predicting maximum ARA production (that is up to $55 \%$ of total lipid) during 10-day growth using an optimized medium containing $(\mathrm{g} / \mathrm{L}) 50$ glucose and 20 fat-free soybean meal (Samadlouie et al., 2012). In the present study, the time courses of fungal growth, phenolic, lipid, ARA accumulation and substrate consumption were investigated. In addition, the expression levele of genes encoding desaturase $(\Delta 5, \Delta 6, \Delta 9, \Delta 12)$, elongase, and malic enzyme involving in ARA and lipid biosynthesis under optimal conditions was investigated. 


\section{Materials and Methods}

\section{Microorganism, inoculum preparation and culture conditions}

Mortierella alpina CBS 754.68 was purchased from Centraalbureau Schimmelcultures (CBS, the Netherlands). The seed culture medium contained $(\mathrm{g} / \mathrm{L})$ : glucose 30 and yeast extract 7 . The seed culture of $100 \mathrm{~mL}$ was incubated at $25^{\circ} \mathrm{C}$ for two days in a gyratory shaker at $185 \mathrm{rpm}$. The fermentation medium was inoculated with $5 \%(\mathrm{v} / \mathrm{v})$ of the mycelium suspension of the seed culture. Fermentation was carried out at $21^{\circ} \mathrm{C}$; $\mathrm{pH} 6$ for ten days with glucose $(50 \mathrm{~g} / \mathrm{L})$ and soy bean meal $(20 \mathrm{~g} / \mathrm{L})$ as carbon and nitrogen resources, respectively.

\section{Analytical methods}

The dinitrosalicylic acid (DNS) method was used to determine the reducing sugar concentration (Miller, 1959). Protein concentration was assayed using the Lowry's method (Lowry et al., 1951). The dry weight of biomass, total phenolic content, total lipids and content of ARA were determined as described in previous publications (Folch et al., 1957; Waterhouse, 2002; Jang et al., 2005; Metcalfe et al., 1996).

\section{RNA extraction, reverse transcription and Real-time PCR}

Total RNA was extracted using the RNA Kit according to the manufacturer's instructions (Invitrogen) The NCBI database was scanned for genes encoding for fatty acid desaturases and elongases. The hints were aligned and the conserved regions were used for primer designing. For malic enzyme encoding gene (GenBank ID: DQ973624.1), only one hint was found which used for primer designing. PCR Primers for mentioned genes and the Housekeeping Gene (actin) were designed using the Gene Runner Design software. The primers for all genes are given in Table 1. cDNA was synthesized using the cDNA synthesis kit (Invitrogen) using oligo (dT) as primers according to the manufacturer's instructions. Expression analysis of genes involving in ARA and lipid biosynthesis was carried out using Real-time PCR. The Real-time PCR mixtures containing cDNA and each primer were heated at $95^{\circ} \mathrm{C}$ for $15 \mathrm{~min}$ and then subjected to 40 cycles consisting of denaturation at $95^{\circ} \mathrm{C}$ for $5 \mathrm{~s}$, annealing at $60^{\circ} \mathrm{C}$ for $20 \mathrm{~s}$, and extension at $72{ }^{\circ} \mathrm{C}$ for $20 \mathrm{~s}$, and finally for an extension of $10 \mathrm{~min}$ at $72{ }^{\circ} \mathrm{C}$. The expression levels of target genes were normalized based on actin encoding gene (Sakuradani et al., 2009) $\left(\Delta \mathrm{Ct}=\mathrm{Ct}_{\text {target gene }}-\mathrm{Ct}_{\text {reference gene }}\right)$. Since the total number of cycles in the Real-Time PCR was 40, for easier interpretation, the $\Delta \mathrm{Ct}$ was converted into $40-\Delta \mathrm{Ct}$ (Czechowski et al., 2004).

\section{Results and Discussion}

\section{Dynamics of substrate consumption and biomass, phenolic, lipid and ARA production}

Reducing sugars consumed slowly in the first days of cultivation followed by quick consumption in the later days of growth. The slow uptake of reducing sugars was probably due to two events; consumption of reducing sugar by the fungus for its growth and metabolic need and, production of reducing sugar by the enzymatic digestion of complex soy bean carbohydrates (Figure 1).

Table 1 - Characteristics of primers used in Real-time PCR

\begin{tabular}{|c|c|c|c|c|c|c|}
\hline Amplicon size & $\mathrm{TM}$ & $\% \mathrm{GC}$ & Primer sequence & Primer & gene & No. \\
\hline \multirow[t]{2}{*}{$200 \mathrm{bp}$} & 52 & 63.2 & GCACTGGACCTGGTACCTC & forward & $\Delta 6$ & 1 \\
\hline & 55 & 55 & GACCCGTGATGATCTGCTTG & Reverse & & \\
\hline \multirow[t]{2}{*}{$224 \mathrm{bp}$} & 53 & 61.3 & GCTCTTGTTCCTGGCTGC & forward & $\Delta 12$ & 2 \\
\hline & 56 & 60 & CGAGTGCGAGATTCTCCAGG & Reverse & & \\
\hline \multirow[t]{2}{*}{$228 \mathrm{bp}$} & 54 & 47.6 & GACGACCTCAACAAGAGCAAA & forward & $\Delta 9$ & 3 \\
\hline & 56 & 55 & CGGTCATCAAAGGGTCCATC & Reverse & & \\
\hline \multirow[t]{2}{*}{$221 \mathrm{bp}$} & 56 & 61.1 & GTTTGGGGCTGCAGATGC & forward & $\Delta 5$ & 4 \\
\hline & 53 & 55 & CAAAGAGCTGCGCGTAGTAG & Reverse & & \\
\hline \multirow[t]{2}{*}{$234 \mathrm{bp}$} & 56 & 57.9 & CCCAAGGTCGGCAAAGTCT & forward & MALCE1 & 5 \\
\hline & 55.5 & 55 & GCGTTGTTCCACAAGCTCTG & Reverse & & \\
\hline \multirow[t]{2}{*}{$221 \mathrm{bp}$} & 55.7 & 47.6 & CCTTAAGAAGAACAACCGCCA & forward & GLELO & 6 \\
\hline & 55.4 & 55 & GCGAACGCGTGATGTAGAAC & Reverse & & \\
\hline \multirow[t]{2}{*}{$230 \mathrm{bp}$} & 53 & 52.4 & CGACAACATGACTGGTACTGC & forward & Malic & 7 \\
\hline & 57 & 52.4 & GCAGGGTTTCCTCAAGCTGAT & Reverse & & \\
\hline \multirow[t]{2}{*}{$200 \mathrm{bp}$} & 54 & 68.8 & CGAGTTGCGTGTCGCC & forward & Actin & 8 \\
\hline & 52 & 55.6 & TGGGAACAGTGTGGGTGA & Reverse & & \\
\hline
\end{tabular}




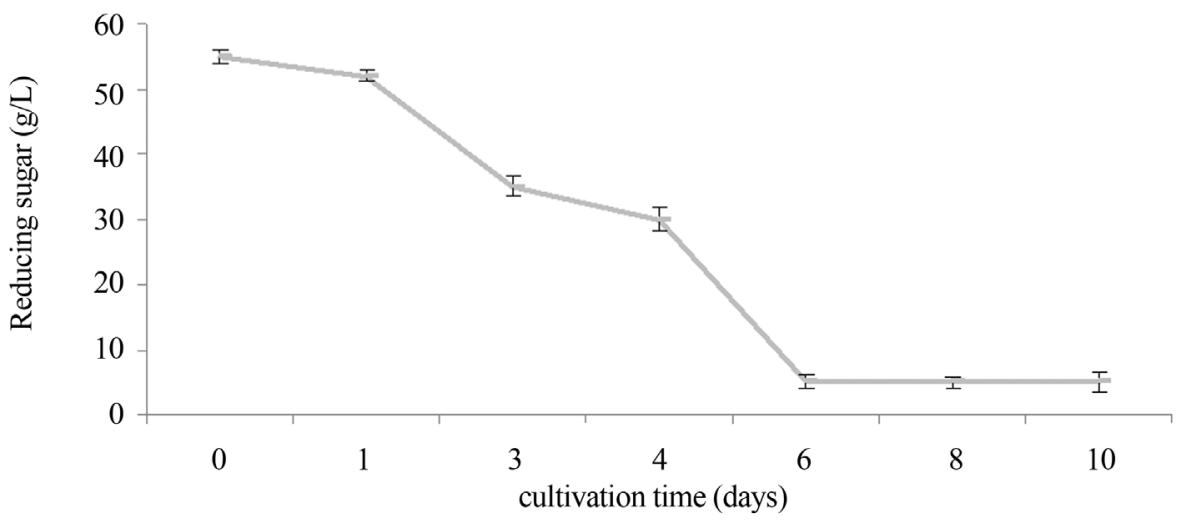

Figure 1 - Time courses of reducing sugar consumption by Mortierella alpina CBS 754.68. The vertical bars represent S.E. of the means of three replications.

The protein source did not deplete but remained in the medium until day 6 . Dynamic analysis showed that the residual glucose was low but the nitrogen sources did not deplete. As soybean is a complex medium containing insoluble protein, these constituents presumably remained until day 6 in the medium (Figure 2).

Time courses of lipid content in biomass were measured (Figures 3). According to these results, the lipid con- tent reached its peak at day 6 . Lipid accumulation increased as reducing sugar significantly decreased from day 4 to day 6 (Figures 1 and 3). Comparison between protein consumption rates and those of lipid production implies that lipid accumulation increased in parallel with reduction in reducing sugar contents (Figures 1, 2 and 3).

Dry biomass yield of Mortierella alpina CBS 754.68 is shown in Figure 4, indicates a substantial increased in the

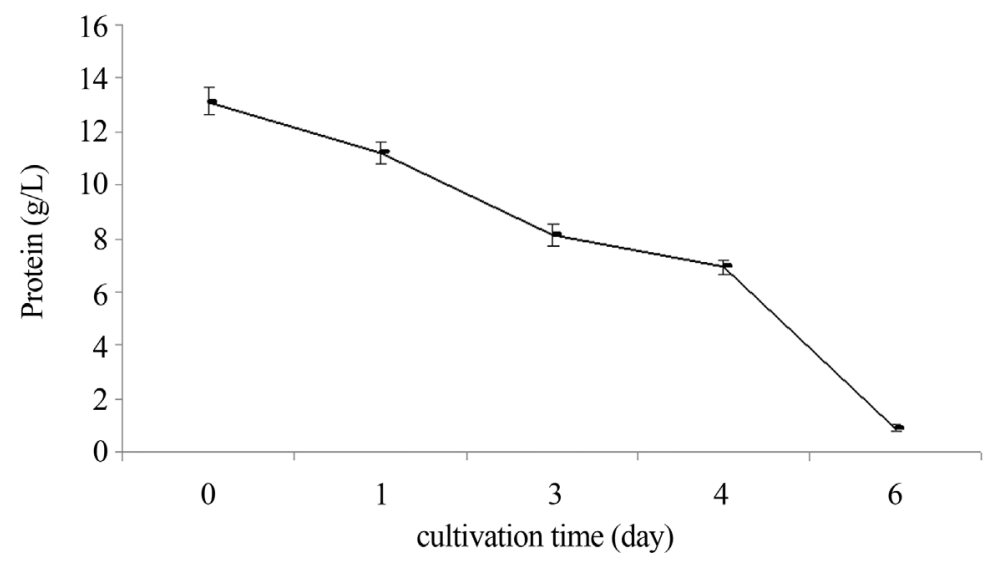

Figure 2 - Time courses of protein consumption by Mortierella alpina. The vertical bars represent S.E. of the means of three replications.

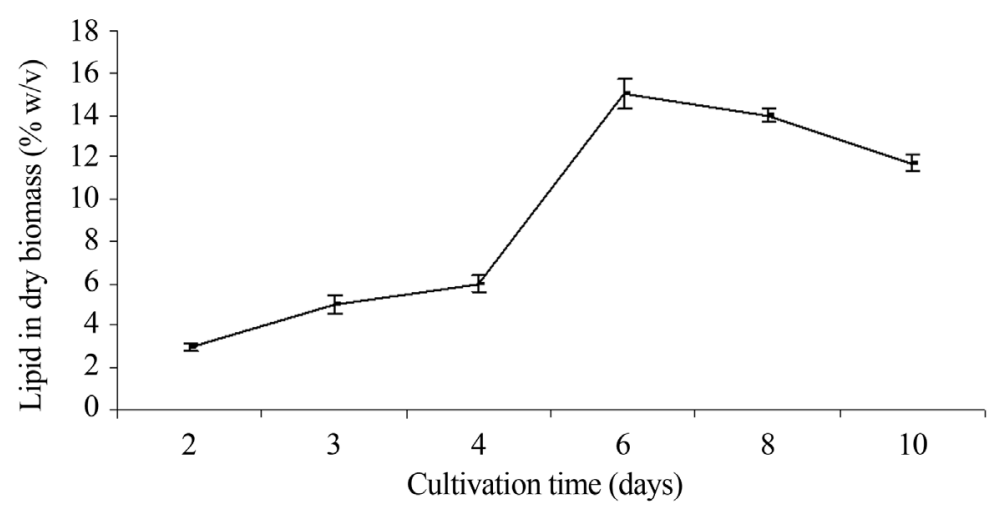

Figure 3 - Time courses of lipid production by Mortierella alpina. The vertical bars represent S.E. of the means of three replications. 


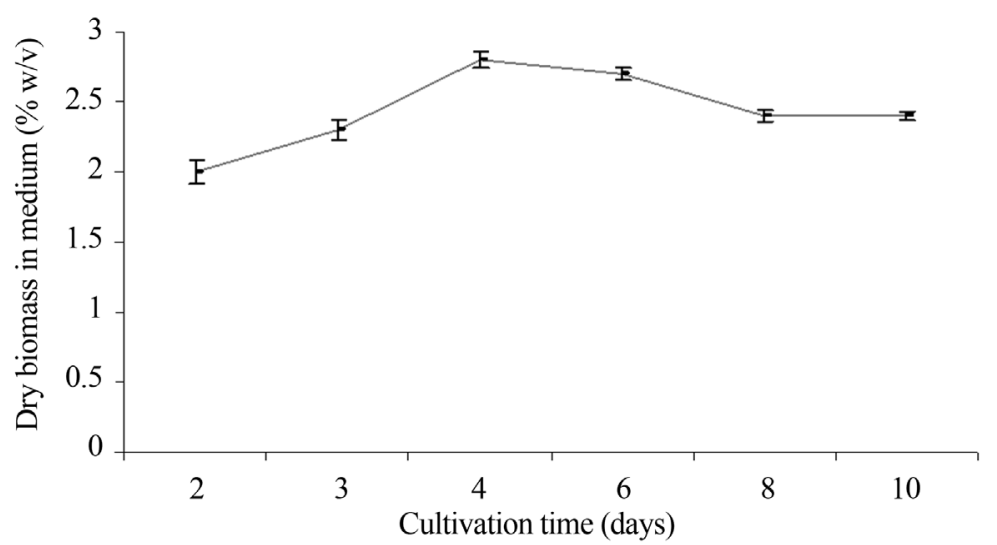

Figure 4 - Time courses of dry biomass production by Mortierella alpina. The vertical bars represent S.E. of the means of three replications.

early days of growth until day 2 . Such increase may be due to the consumption and digestion of insoluble protein and complex carbohydrates present in soybean. However, the rate of yield production reduced after day 4 probably due to depletion of these substrates. Under these conditions, lipid accumulation increased substantially concomitant with the increased utilization of readily-digestible substrates such as soluble protein and monosaccharides (Figures 1 and 3).

It should be noted that while the biomass dry weight reached a plateau at the end of fermentation, the lipid amount decreased substantially (Figures 3 and 4). This suggests that lipids are the best macromolecules that store chemical energy and this is probably why they are deposited in Mortierella and many other oleaginous fungi (Weete, 1981). On the other hand, the stationary phase itself is an excellent phase for synthesis of fatty acids especially ARA (Jin et al., 2007).

As shown in Figure 5, a substantial increase of ARA content in lipids occurred after the lipids decreased in biomass at the end of fermentation (Figures 3 and 5). The lipid content decreased from $15 \%$ at day 6 to $11.7 \%$ at day 10 and ARA content increased from $34 \%$ to $55 \%$. These re- sults are in agreement with the findings reported by (Zhu et al., 2006; Eroshin et al., 2002) demonstrating a great increase of ARA content in lipids after glucose exhaustion and lipid yield decrease. Also these results are in full accordance with other organisms. For instance, Funtikova and Mysyakina (1997) reported that gamma linolenic acid content in Mortierella spinosa becomes relatively low during lipid accumulation and increases as the lipids degrade.

The results presented in our study demonstrated that Mortierella alpina CBS 754.98 has high phenolic content and thus could be potential rich sources of natural antioxidants (Figures 6). The phenolic compounds appear to have an important role in reducing lipid oxidation, associated with their antioxidant activity (Samadloiy et al., 2008). However, the phenolic content had no association with lipid and ARA accumulation and was only related to cell growth (Figures 4 and 6). The maximum phenolic yield was obtained after 4 days of cultivation $(73 \mathrm{mg}$ gallic acid equivalents/ $100 \mathrm{~g}$ ) which is a decreasing trend, thereafter compared to other edible mushroom species such as beefsteak fungus (Ribeiro et al., 2007). Mortierella alpina CBS 754.98 apparently contains more phenolic compounds,

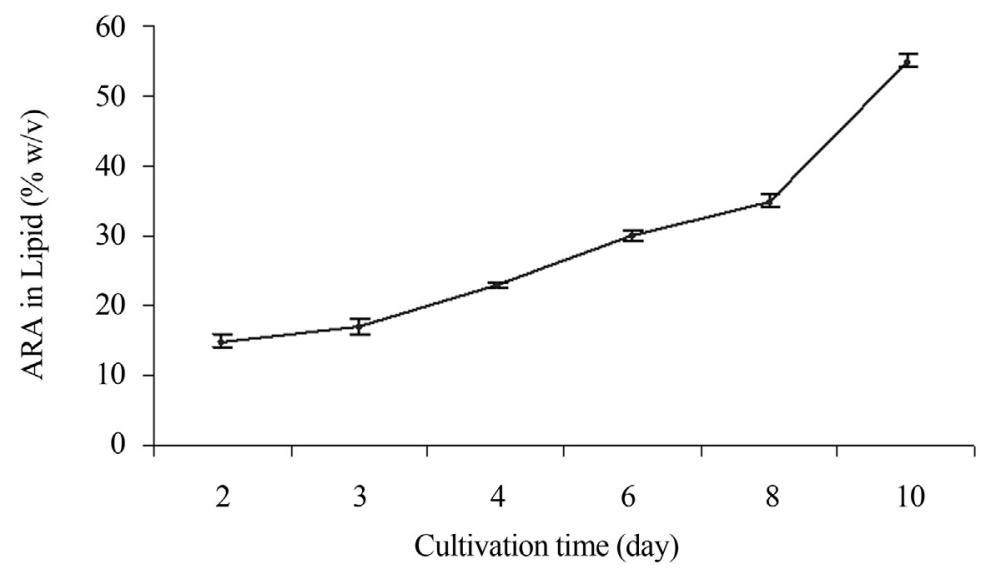

Figure 5 - Time courses of ARA production by Mortierella alpina. The vertical bars represent S.E. of the means of three replications. 


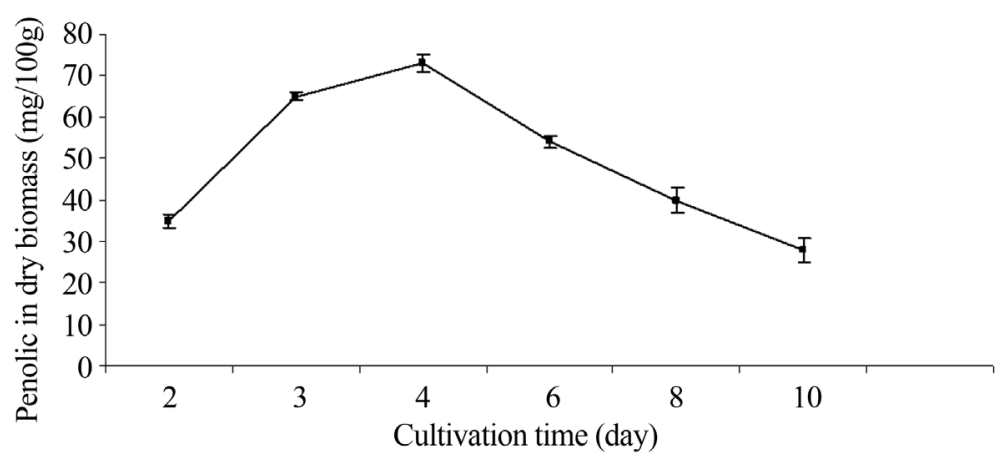

Figure 6 - Time courses of phenolic production by Mortierella alpina. The vertical bars represent S.E. of the means of three replications.

which highlights the importance of this fungus as a rich source for these compounds.

Fakas et al. (2008) reported that hydrogen peroxide content in the lipid of the oleaginous fungus increased from the exponential step to the stationary phase. It is conceivable from our results that this increased level of hydrogen peroxide may be related to the overall reduction of intracellular phenolic content and increased desaturation of fatty acids levels at the end of fermentation.

\section{The expression levels of desaturase and elongase encoding genes}

At days 2 and 4, in which dry biomass increased, the ARA content slowly increased in parallel with reduced expression of $\Delta 12$ encoding gene at day 2 and GLELO encoding gene at days 2 and 4 . In fact, at the same day of cultivation, intermediate fatty acids contents (such as stearic acid, oleic acid and linoleic acid) increased substantially concomitant with decreases in the expression level of the two above mentioned genes. According to Gray et al. (2002), fatty acids in cell membranes are usually 18 carbon fatty acids.

We found that intermediate unsaturated fatty acids critical for cell growth (such as stearic acid, oleic acid, linoleic acid) were increased. Therefore, the reduced levels of $\triangle 12$ and GLELO encoding genes expression in the growth phase could be a reflection of their role in the protection of Mortierella alpina CBS 754.68 through membrane fluidity.

The expression levels of the desaturase and elongase encoding genes were the lowest when carbon and protein contents reduced to 5 and $1 \mathrm{~g} / \mathrm{L}$ at day 6 , respectively. These genes were highly expressed at day 8 when an accelerated reduction of lipid content in dry biomass was observed (Figures 7 and 8). It is believed that the shift in the energy source from glucose to lipid could be the main factor leading to the increased rates of desaturase and GLELO encoding genes expression at day 8 . The analysis of expression of desaturase and GLELO encoding genes indicated that the elongase converting $18: 3(n-6)$ to $20: 3(n-6)$ is a rate-limiting enzyme in the ARA biosynthesis in the early growth especially until day 4 . However, at the end of growth when the energy source shifted to lipids, the GLELO encoding gene no longer acted as the rate limiting gene in the biosynthesis of ARA.

\section{The expression levels of malic enzyme encoding gene}

The expression levele of the malic enzyme encoding gene was the highest at days 2 and 4 (Figure 9), which was

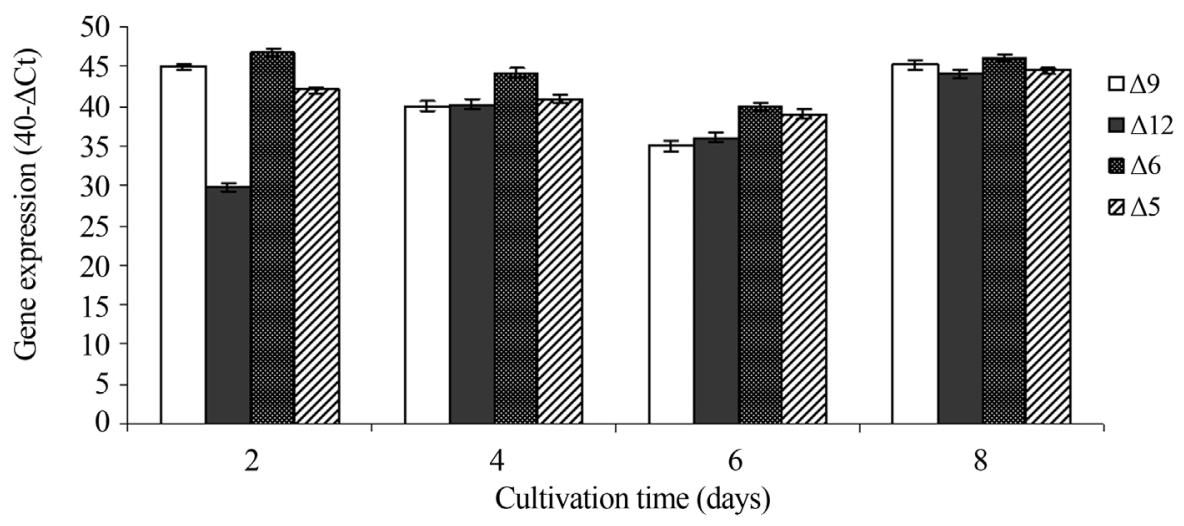

Figure 7 - Gene expression (40- $\Delta \mathrm{Ct}$ ) of desaturase encoding gene by Real-time PCR analysis. Real-time PCR amplification of actin was used to normalize expression of the genes under identical conditions. The vertical bars represent S.E. of the means of three replications. 


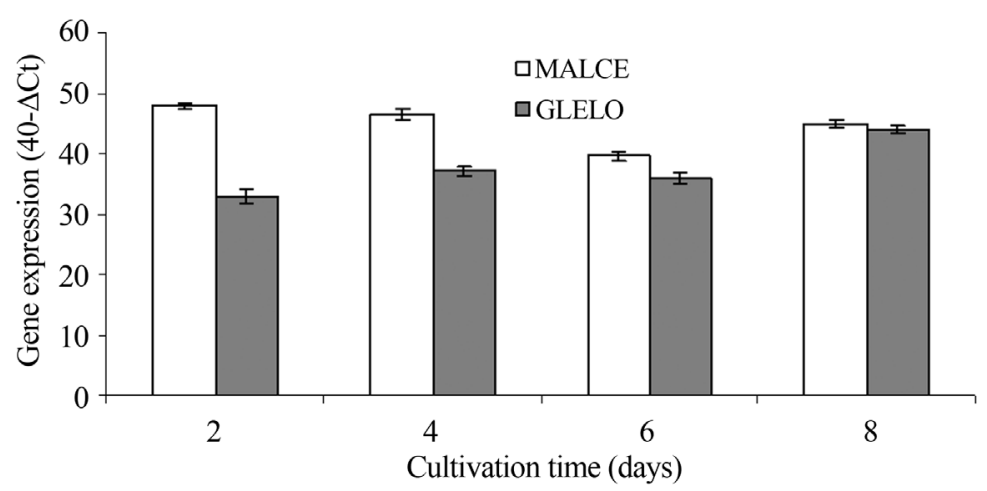

Figure 8 - Gene expression (40- $\Delta \mathrm{Ct}$ ) of elongase encoding genes by Real-time PCR analysis. Real-time PCR amplification of actin was used to normalize expression of the genes under identical conditions. The vertical bars represent S.E. of the means of three replications.

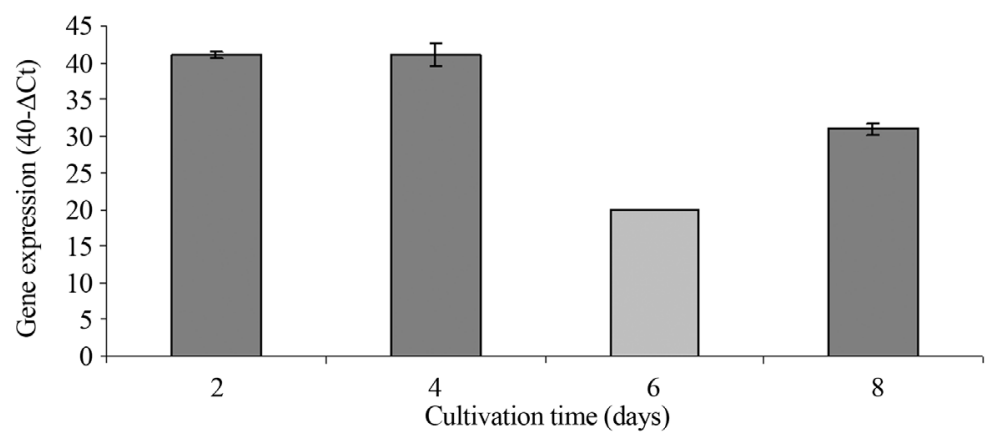

Figure 9 - Gene expression (40- $\Delta \mathrm{Ct}$ ) of malic enzyme encoding gene by Real-time PCR analysis. Real-time PCR amplification of actin was used to normalize expression of the gene under identical conditions. The vertical bars represent S.E. of the means of three replications.

in parallel with increasing in the lipid and biomass contents in the early days of cultivation. This might imply that malic enzyme encoding gene is closely bound to lipid and biomass biosynthesis. The results were similar to those obtained by Wynn et al., 1999 who reported malic enzyme which plays an important role in the provision of NADPH for lipid biosynthesis in Mortierella alpina. Under these conditions other fatty acids were slowly converted to ARA. Thus, the increase in lipid accumulation may have the most profound effect on lipid composition. These results are in agreement with studies demonstrating that PUFA concentration decreases along with lipid content increase (Hansson and Dostalek, 1988; Hansson et al., 1989; Chen and Chang, 1996; Gema et al., 2002; Papanikolaou et al., 2004; Fakas et al., 2009). Reducing sugar and protein content reduced to 5 and $1 \mathrm{~g} / \mathrm{L}$ at day 6 , respectively, resulting in a low basal levele of expression of the malic enzyme encoding gene $(\mathrm{Ct}=40)$ followed by inhibition of lipid production (Figures 1, 3 and 9). The results were similar to those obtained by Wynn and Ratledge (2000) who reported a relatively increased activity for the malic enzyme following Mortierella strain growth on glucose. The expression of the mentioned gene increased at day 8 and its $40-\Delta \mathrm{Ct}$ reached 31 (Figure 9). This increase in the expression of the malic enzyme encoding gene could be due to its important role in providing NADPH for ARA production (Figures 5 and 9).
The results are in accordance with those obtained by Kendrick and Ratledge (1992) who reported that the malic enzyme in oleaginous species acts as a provider of NADPH for fatty acid desaturation and even elongation.

There are two assumptions for ARA accumulation in oleaginous microorganisms in batch culture. According to Eroshin et al. (2002) ARA content in lipids increases as a result of conversion of other fatty acids. In this study, the increase in the ARA content in the lipids at the end of fermentation could be related to the overall reduction of cellular metabolic activity. This down-regulation would then restrict carbon flow through the metabolic pathway reducing the expression of the malic enzyme encoding gene and production of reducing powers (e.g. NADH, NADPH). According to Georgiou et al. (2006) the diminished concentration of cell reductants would increase the intracellular oxygen concentrations. Therefore, it can be concluded that the elevated oxygen concentrations observed in this study resulted in the increased expression of GLELO and desaturase encoding genes which converts other fatty acids to ARA.

\section{Conclusion}

The results of this study showed that the expression of our target genes depends on culture conditions. It can be concluded that the ARA accumulation increases in parallel 
with reduced expression of the malic enzyme encoding gene that coincided with reduced levels of lipid in dry biomass.

\section{References}

Chen H, Chang C (1996) Production of $\gamma$-linolenic acid by the fungus Cunninghamella echinulata CCRC 31840. Biotechnol Prog 12:338-341.

Czechowski T, Bari RP, Stitt M, Scheible WR, Udvardi MK (2004) Real-time RT-PCR profiling of over 1400 Arabidopsis transcription factors: unprecedented sensitivity reveals novel root- and shoot-specific genes. Plant J 38:366-379.

Eroshin VK, Dedyukhina EG, Satroutdinov AD, Chistyakova TI (2002) Growth-coupled lipid synthesis in Mortierella alpina LPM 301 a producer of arachidonic acid. Microbiology 71:169-172.

Fakas S, Papapostolou L, Papanikolaou S, Georgiou CD (2008) Susceptibility to peroxidation of the major mycelial lipid of Cunninghamella echinulata. Eur J Lipid Sci Technol 110:1062-1067.

Fakas S, Papanikolaou S, Batsos A, Galiotou-Panayotou M, Mallouchos A, Aggelis G (2009) Evaluating renewable carbon sources as substrates for single cell lipid production by Cunninghamella echinulata and Mortierella isabellina. Biomass and Bioenergy 33:573-580.

Folch J, Lees M, Stanley GHS (1957) A simple method for the isolation and purification of total lipids from animal tissues. J Biol Chem 226:497-509.

Funtikova NS, Mysyakina ISk (1997) Synthesis of gammalinolenic acid by mucaraceous fungi utilizing exogenous fatty acids. Microbiol 66:76-79.

Gema H, Kavadia A, Dimou D, Tsagou V, Komaitis M, Aggelis G (2002) Production of $\gamma$-linolenic acid by Cunninghamella echinulata cultivated on glucose and orange peel. Appl Microbiol Biotechnol 58:303-307.

Georgiou CD, Patsoukis N, Papapostolou I, Zervoudakis G (2006) Sclerotial metamorphosis in filamentous fungi is induced by oxidative stress. Integr comp Biol 46:691-712.

Gray J, Groeschler S, Le T, Gonzalez Z (2002) “Membrane Structure"(SWF). Davidson College. Retrieved 2007-01-11.

Hansson L, Dostalek M, Sorenby B (1989) Production of $\gamma$-linolenic acid by the fungus Mucor rouxii in fed-batch and continuous culture. Appl Microbiol Biotechnol 31:223-237.

Hansson L, Dostalek M (1988) Effect of culture conditions on mycelial growth and production of $\gamma$-linolenic acid by the fungus Mortierella ramanniana. Appl Microbiol Biotechnol 28:240-246.

Jang HD, Lin YY, Yang SS (2005) Effect of culture medium and condition on polyunsaturated fatty acid production by Mortierella alpina. Bioresource Technol 96:1633-1644.

Jin MJ, Huang H, Zhang K, Yan J, Gao Z (2007) Metabolic flux analysis on arachidonic acid fermentation. J Chem Eng Chinese Univ 21:316-321.

Kendrick A, Ratledge C (1992) Lipids of selected molds grown for production of $n_{-} 3$ and $n_{-} 6$ polyunsaturated fatty acids. Lipids. 27:15-20.
Lowry OH, Rosebrough NJ, Farr AL, Randall RJ (1951) Protein measurement with the folin-phenol reagents. J Biol Chem 193:265-275.

Miller GL (1959) Use of dinitrosalicylic acid reagent for determination of reducing sugar. Anal Chem 31:426-428.

Metcalfe LD, Schmitz AA, Pelka JR (1996) Rapid preparation of fatty acid esters from lipids for gas chromatographic analysis. Anal Chem 38:514-515.

Papanikolaou S, Sarantou S, Komaitis M, Aggelis G (2004) Repression of reserve lipid turnover in Cunninghamella echinulata and Mortierella isabellina cultivated in multiplelimited media. J Appl Microbiol 97:867-875.

Ribeiro B, Valentao P, Baptista P, Seabra RM, Andrade PB (2007) Phenolic compounds, organic acids profiles and antioxidative properties of beefsteak fungus (Fistulina hepatica). Food and Chemical Toxicology 45:1805-1813.

Sakuradani E, Nojiri M, Suzuki H, Shimizu S (2009) Identification of a novel fatty acid elongase with a wide substrate specificity from arachidonic acid-producing fungus Mortierella alpina 1S-4. Appl Microbiol Biotechnol 84:709-716.

Samadloiy HR, Azizi MH, Barzegar M (2008) Physicochemical quality of seeds of pomegranate cultivar (Punica granatum L.) grown in Iran and antioxidative activity of their phenolic component. J Food Sci Technol 45:190-192.

Samadlouie HR, Hamidi-Esfahani Z, Alavi SM, Soltani-Najafabadi M, Sahari MA, Abbasi S (2012) Statistical approach to optimization of fermentative production of lipid and arachidonic acid from Mortierella alpina CBS 754.68. African journal of microbiology research 6:1559-1567.

Shimizu S, Sakuradani E, Ogawa J (2003) Production of functional lipids by microorganisms: Arachidonic acid and related polyunsaturated fatty acids, and conjugated fatty acids. Oleoscience 3:129-139.

Sing A, Ward OP (1997) Production of high yields of arachidonic acid in fed batch system by Mortierella alpina ATCC 32222. Appl Microbiol Biotechnol 48:1-5.

Waterhouse AL (2002) Wine phenolics. Annals of the New York Academy of Sciences. 957:21-36.

Weete JD (1981) Lipids in fungal growth and reproduction. In: Turian G., Hohl, H.R. (eds), The Fungal Spore: Morphogenetic Controls. Academic Press, San Diego, pp 463-485.

Wynn JP, Hamid AA, Ratledge C (1999) The role of malic enzyme in the regulation of lipid accumulation in filamentous fungi. Microbiology 145:1911-1917.

Wynn JP, Ratledge C (2000) Evidence that the rate-limiting step for the biosynthesis of arachidonic acid in Mortierella alpina is at the levele of the 18:3 to 20:3 elongase. Microbiol 146:2325-2331.

Zhangy Y, Ratledge C (2008) Multiple isoforms of malic enzyme in the oleaginous fungus, Mortierella alpina. Mycological research 112:725-730.

Zhu M, Yu LJ, Li W, Zhou PP, Li CY (2006) Optimization of arachidonic acid production by fed-batch culture of Mortierella alpina based on dynamic analysis. Enzyme and Microbial Technology 38:735-740.

All the content of the journal, except where otherwise noted, is licensed under a Creative Commons License CC BY-NC. 